\title{
A Orfandade Política da Defesa
}

\section{The Political Orphanage of Defence}

Rev. Bra. Est. Def. v. 3, nº 1, jan./jun. 2016, p. 15-19

ISSN 2358-3932

\section{MARIO CESAR FLORES}

Este artigo é adaptação para a Revista Brasileira de Estudos de Defesa de artigo meu, com o mesmo título, publicado no O Estado de São Paulo, em 8 de junho de 2016. Abordo assunto já objeto de artigos anteriores, de minha autoria, cuja solução é condicionante fundamental para o encaminhamento sensato do tema defesa, no Brasil: a apatia nacional. Seu alvo é o mundo civil, em particular o político, responsável pela condução do país.

O conceito de defesa varia de país para país. Pode significar a defesa tradicional contra a agressão clássica, de outro país. Na contramão do significado rigoroso da palavra, pode-se estender ao uso agressivo da força, para a realização de objetivos nacionais e/ou a título de defesa preventiva. Pode ser apenas o controle rotineiro (em que se destaca a repressão de delitos transnacionais) da fronteira terrestre, mar costeiro e espaço aéreo. $\mathrm{E}$ no mundo integrado, em que fatos locais repercutem distante, inclui outro estupro semântico: a intervenção em defesa da ordem internacional, em geral "coincidente" com o interesse nacional de quem intervém e/ou em defesa dos direitos de povo vítima de desordem traumática (Otan x Sérvia nos anos 1990, vários países x EI hoje).

Na maioria dos países - praticamente em todos - impõe-se uma combinação dessas versões do conceito, em dosagem relativa definida por seus problemas. Qual seria a combinação adequada ao Brasil? Descartando de imediato o uso agressivo da força, incompatível com o caráter brasileiro e com nossa tradição propensa ao pacifismo, esbocemos uma ideia superficial da resposta, em que transparece a dificuldade de sua formulação, entre outras razões, se não principalmente, devido ao refletido no título do artigo.

A atual ausência de ameaça externa (de Estado) tende a reduzir o peso relativo da defesa clássica. Mas a dinâmica da história e, neste século 21 , a turbulência inerente à integração global sugerem que essa situação de tranquilidade internacional, no seu sentido clássico, não é segura no tempo. Embora não existam razões ponderáveis, de curto prazo, a insegurança

Mario Cesar Flores - Almirante de Esquadra Reformado da Marinha do Brasil. E-mail: marioflores@ uol.com.br. 
em assunto tão radical indica que o Brasil deve dispor de poder militar comedido, mas convincente e moderno - a tecnologia pesa hoje sensivelmente mais que a dimensão, preponderante no passado -, capaz de dissuadir tal tipo de ameaça e de abortá-la, se concretizada, assim indicando ser a negociação o melhor caminho para a solução de contenciosos.

Essa é a razão fundamental das Forças Armadas e sem ela caberia questionar a própria existência das Forças, mas não é tudo. Pressionado pelo cotidiano transnacional conturbado, a que a política, a mídia e o povo são mais sensíveis, vem aumentando o peso relativo de problemas transnacionais, em princípio mais de natureza parapolicial do que propriamente de defesa. Não havendo no Brasil guarda-costeira, força de segurança de fronteira e guarda nacional aérea, o uso das Forças Armadas faz-se necessário nesse contexto operacional, de complementar a total, em circunstâncias e cenários em que a atuação policial não existe, ou é (e continuará sendo) frágil: mar costeiro, espaço aéreo e algumas fronteiras terrestres, em particular a imensa fronteira amazônica e do centro-oeste. Nosso ideário de defesa deve, portanto, considerar as Forças Armadas também nos papéis de guarda-costeira, guarda nacional aérea e controle de fronteiras - controle que se estende a regiões interiores, em que a presença apenas policial é precária, como é o vasto cenário fluvial da bacia amazônica.

Raciocínio similar se aplica às Forças Armadas como complemento aos (ou em substituição dos) sistemas policiais na ordem interna, em circunstâncias excepcionais que justifiquem a atuação das Forças, de acordo com a moldura constitucional a respeito. Embora não se enquadre na ideia clássica de defesa, essa hipótese de uso das Forças é uma realidade a ser pensada. Já dispomos de embrião para isso - a Força de Segurança Nacional, ainda a ser consolidada -, mas a necessidade de atuação militar por ora não pode ser descartada.

Quanto à ordem mundo afora, o Brasil tem apoiado as decisões da ONU a respeito (casos relevantes: Haiti hoje, batalhão Suez há 60 anos) e provavelmente continuará apoiando, tanto as decisões da ONU, como também as de outras organizações credenciadas - a OEA, por exemplo -, em expressividade crescente com o desenvolvimento do país e de sua presença em assuntos internacionais. Expressividade crescente e até mesmo protagônica no seu entorno geoestratégico, mas coadjuvante ou ao menos simbólica, no mundo. Essa hipótese de uso das Forças obviamente induz peculiaridades ponderáveis no preparo militar.

A complexidade dinâmica do conceito de defesa aplicável ao Brasil defesa clássica, atuação parapolicial e, complementarmente, apoio a decisões internacionais - implica numa questão também complexa, mais ainda em época de dramática restrição orçamentária: o uso de recursos escassos 
nesta ou naquela orientação, que depende de competente, sensata e responsável avaliação relativa da provável necessidade de atuação das Forças Armadas, no presente e futuro imaginável.

Submarino ou navio-patrulha costeiro? Caça gripen ou super-tucano? Carro de combate e míssil antiaéreo ou o preparo para atividades parapoliciais nas fronteiras e ordem interna? O ideal seria " $e$ " ao invés de "ou", sem interrogação, mas esse ideal é inviável no padrão orçamentário hoje possível. É compreensível a tendência a aceitar, por exemplo, que quatro navios-patrulha costeiros estariam sendo mais úteis agora do que um submarino - admitamos custo similar para este raciocínio. Mas essa tendência atende com segurança o longo prazo? Entra aí um fator de grande peso: são necessários muitos anos (e recursos vultosos) para construir Forças Armadas tecnicamente modernas. Não há como improvisá-las, à semelhança do que ocorria na época do armamento simples - lanças e espadas no passado remoto, fuzis e metralhadoras rudimentares já na $1^{\mathrm{a}}$ Guerra Mundial -, quando a mobilização humana e seu treinamento sumário para o uso de equipamento simples eram mais importantes do que a tecnologia do armamento disponível.

Chegamos ao fundamental do artigo: o encaminhamento dessa questão, que implica na identificação e avaliação competente e responsável do que é ou possa vir a ser problema brasileiro de defesa no seu sentido amplo enunciado no início do artigo, do presente ao futuro imaginável, não é assunto apenas corporativo militar, como praticamente vem sendo na nossa realidade - e convém deixar claro, não porque os militares assim desejam. Diz respeito também ao poder político eleito pela nação e credenciado a representá-la, ao Itamaraty com suas perspectivas de política internacional, aos diversos órgãos públicos com encargos que têm a ver com a defesa lato sensu e, como contribuição societária, às instituições de altos estudos políticos, sociais e econômicos. É esse amálgama de visões, criteriosamente avaliadas e integradas, que deve orientar o preparo militar, cabendo aos militares a formulação concreta dos projetos que atendam ao sentimento nacional como acima esboçado e aos políticos, assegurar-lhes os meios adequados.

Isso não vem acontecendo. Na nossa história (com maior tendência nos últimos anos), a indiferença do tema, pela política e pela sociedade em geral, tem inibido a formulação do preparo militar que, respondendo criteriosamente à razão de ser básica das Forças, sem exageros ufanistas, mas também sem menoscabar hipóteses plausíveis de riscos futuros, inerentes ao Brasil na região e no mundo, atenda também as atividades que, embora classificáveis mais como de segurança, ou parapoliciais, são exigidas das Forças - nas fronteiras vulneráveis, no mar costeiro, no espaço aéreo e em cenários fluviais abrasados, em regime rotineiro, e eventualmente na segu- 
rança interna. Trata-se evidentemente de uma equação política (e administrativa) complexa, cuja solução depende de estadistas competentes e bem assessorados, com conhecimento realista do presente e visão do futuro.

É difícil superar a indiferença no hoje tumultuado clima político interno, em que a questão da defesa nacional praticamente não vem tendo espaço, sendo sumariamente ignorada - situação exemplificada nesses exemplos um tanto exagerados, mas que refletem simbolicamente a realidade consentânea com o ânimo nacional: a Marinha é pretendida como fiscalizadora do uso do jet-ski em praias, o Exército como polícia de favela no Rio de Janeiro e a Força Aérea como transportadora de autoridades. Mas a superação precisa acontecer, para que o país possa contar com uma base conceitual político-estratégica e um poder militar credíveis e respeitados. As ideias sobre defesa em documentos como a Estratégia Nacional de Defesa e a Política Nacional de Defesa e seus desdobramentos em projetos de execução passarão a ser aceitas (e apoiadas) pelo poder político (e pela administração pública) mais por concordância consciente do que "no embalo" do desinteresse, do sentimento de que "aquilo" pode ser aprovado sem preocupações quanto à execução porque não é mesmo "para valer”, como aparenta acontecer hoje. Passarão a ser ideias sancionadas politicamente, como ocorre nos países desenvolvidos e influentes no mundo, onde defesa nacional é preocupação que transcende as Forças Armadas, está presente no quadro mental político. Ademais, a sanção política é condição para que a continuidade do preparo militar sensatamente pensado ocorra sem os graves tropeços orçamentários, que vêm acontecendo sistematicamente.

Haverá então respaldo para a presença brasileira ativa na configuração e na implantação da ordem global integrada do século XXI, para a pretensão do Brasil como membro permanente do Conselho de Segurança da ONU e, internamente, para o progresso em tranquilidade política e social. Terá cessado a orfandade política da defesa nacional e com ela o sentimento equivocado, de que defesa nacional é assunto apenas militar. Não é demais insistir: sua dimensão política é responsabilidade política, que vem sendo menoscabada ao longo dos últimos decênios, praticamente ignorada hoje, quando o sufoco orçamentário se vê apoiado pela apatia política pelo tema. Em alguns casos, mais do que apatia: pela antipatia.

Este artigo não aborda algumas atribuições subsidiárias das Forças Armadas, entre elas a segurança da navegação aquaviária e aérea, a cooperação na defesa civil e por aí vai. Elas não dizem respeito à defesa nacional, mas devem ser consideradas com responsabilidade, de acordo com as condições nacionais que possam exigir a contribuição militar - mutável ao longo de tempo, mas por ora particularmente essencial no concernente à navegação aquaviária e aérea. 


\section{RESUMO}

Ensaio do Almirante-de-Esquadra Reformado Mario Cesar Flores que aborda assunto já objeto de artigos anteriores, de sua autoria, cuja solução é condicionante fundamental para o encaminhamento sensato do tema defesa, no Brasil: a apatia nacional. Seu alvo é o mundo civil, em particular o político, responsável pela condução do país.

Palavras-chave: Política de Defesa; Relação Civil Militar; Forças Armadas do Brasil.

\section{ABSTRACT}

Essay from the Retired Admiral Mario Cesar Flores, from the Brazilian Navy, that addresses a theme already developed in previous articles of his own, which solution is of elementary condition for the sensible treatment of the National Defense theme in Brazil: national apathy. His target is the civilian world, in particular the political world, responsible for running the country.

Keywords: Defense Polity; Military-Civilian Relationship; Brazilian Armed Forces. 